\title{
Simulating the impact of Belt and Road initiative and other major developments in Myanmar on an ambassador felid, the clouded leopard, Neofelis nebulosa
}

\author{
Żaneta Kaszta • Samuel A. Cushman · Saw Htun • Hla Naing • \\ Dawn Burnham $\cdot$ David W. Macdonald
}

Received: 27 June 2019/Accepted: 22 January 2020/Published online: 8 February 2020

(C) The Author(s) 2020

\begin{abstract}
Context After decades of political and economic isolation, Myanmar is now the focus of large international investments, particularly from China, which raises questions of how to balance national development with safeguarding the Indo-Burma biodiversity hotspot.

Objective To evaluate the impact of five major developments in Myanmar on forest ecosystems, using clouded leopard as a focal and umbrella species for wider biodiversity conservation.
\end{abstract}

Electronic supplementary material The online version of this article (https://doi.org/10.1007/s10980-020-00976-z) contains supplementary material, which is available to authorized users.

Ż. Kaszta $(\bowtie) \cdot$ S. A. Cushman · D. Burnham .

D. W. Macdonald

Wildlife Conservation Research Unit (WildCRU),

Department of Zoology, University of Oxford, The

Recanati-Kaplan Centre, Tubney House,

Tubney OX13 5QL, UK

e-mail: zaneta.kaszta@zoo.ox.ac.uk

S. A. Cushman

USDA Forest Service, Rocky Mountain Research Station,

2500 S. Pine Knoll Dr, Flagstaff, AZ 86001, USA

S. Htun $\cdot$ H. Naing

Wildlife Conservation Society Myanmar Program, Aye

Yeik Mon 1st Street, Ward 3, Building C1 Hlaing

Township, Yangon 11051, Myanmar
Methods Based on an empirical habitat relationships model, we identified core areas and corridors in Myanmar, and compared them across the development scenarios. We simulated population dynamics and genetic diversity in each scenario using an individualbased, spatially explicit cost-distance population genetics model.

Results The predicted current clouded leopard population may be larger than the current carrying capacity of the landscape, raising the possibility that the species' population has not yet equilibrated with recent habitat loss and degradation. All the developments combined resulted in $36 \%$ decrease in landscape connectivity and $29 \%$ decrease in simulated clouded leopard population size, including substantial reduction in genetic diversity. Each development was predicted to have a negative effect; however, emerging economic zones had disproportionally large impacts $(-24 \%$ in connectivity and $-25 \%$ in population size), resulting in fragmentation of the largest core areas. Similarly, the Indian Highway and Silk Road caused fragmentation of the largest core habitats, and the Pipeline Railroad significantly decreased connectivity in the main stronghold for clouded leopards.

Conclusions Spatially-explicit assessments like the one presented here provide quantitative evaluation on development impacts and help optimize the trade-offs between development and conservation. The rapid and increasing development of Myanmar and surrounding Southeast Asian nations pose an enormous threat to 
the biodiversity of the region. Optimizing the trade-off between development goals and conservation is essential to minimize the effects of rapid land use change on biodiversity.

Keywords Cumulative resistant kernels - CDPOP . UNICOR · Connectivity · Development scenarios · Resistance $\cdot$ Population dynamics

\section{Introduction}

Southeast Asia is experiencing the highest development growth and deforestation rates in the world, while also harbouring a vast richness of biodiversity. At the current deforestation rate, within 100 years the region could lose three quarters of its original forests and up to $42 \%$ of its biodiversity (Sodhi et al. 2004). Myanmar, due to its recent history and geopolitical location, might be the Southeast Asian nation that is most vulnerable to these rapid changes (Webb et al. 2012).

The economic and political isolation of Myanmar over the past 70 years has resulted in a complex mixture of conditions. First and foremost, from the perspective of conservation, it resulted in very low economic and population growth as compared to other nations in the region. One unintended consequence of this is that Myanmar today retains a substantially higher amount of native forest and the largest extents of unfragmented forest ecosystems and the wildlife populations they support of all of Southeast Asia (Macdonald et al. 2019).

Political and economic isolation, however, also have created several challenges for environmental governance. The country is experiencing unsustainable and accelerating exploitation of timber and minerals. At the same time, there are negligible environmental safeguards and a poorly enforced and under-resourced network of protected areas. As a result there are ongoing rapid declines in wildlife populations (Webb et al. 2012).

Forest, which covered 77\% of Myanmar's territory at the time of its independence in 1948, has decreased from $60 \%$ in 1990 to $44.2 \%$ in 2015, with an annual deforestation rate of $1.2 \%$ between 1990 to 2015 (FAO 2015). However, the highest annual forest loss was recorded between 2010 and 2015 (1.8\%)-just after the country established a new government and opened its markets to international trade (FAO 2015). Even though Myanmar has one of the highest rates of deforestation in SE Asia, the country has the most extensive forest cover remaining in Southern or Southeast Asia, from tropical to alpine forest, $11 \%$ of which represents a primary forest (FAO 2015), and is the core of the globally important and highly threatened Indo-Burma biodiversity hotspot (Tordoff et al. 2012; Hughes 2017).

The main threat to the Myanmar's wildlife, however, may be yet to come. Located between two growing economic superpowers-China and IndiaMyanmar, in contrast, has some of the lowest human development and governance indicators in the world (UNDP 2018). Myanmar's neighbours view the economic liberalization of the country as an opportunity for massive investments focused on extraction of raw materials, export of industries that cause environmental pollution and drive land use change, as well as investments in intensifying and expanding the agricultural sector (Webb et al. 2012). The establishment of a new quasi-democratic government in 2011, followed by reduction of international sanctions and increase of trade (e.g., through several trade pacts, like China-ASEAN Free Trade Agreement) have resulted in an enormous acceleration of economic development in Myanmar, in particular large-scale agricultural and industrial development. Without far-sighted policymaking and thoughtful land use planning, the rapid development of Myanmar will likely lead to rapid loss of the nation's remaining natural forest and the biodiversity it supports.

To foster this nascent economic renaissance, Myanmar has actively drafted new land and investment laws and created special economic zones (Schmidt 2012). China is the major investor in Myanmar and from 2004 to 2015 the volume of China's investments in Myanmar increased nearly 200 times, reaching US $\$ 18$ billion (Gong 2018). Chinese investments in Myanmar focus mainly on the energy and metals sectors and often include projects where other parties are unlikely to invest because of environmental and humanitarian concerns, or financial risk (Lamb and Dao 2017). The Chinese projects have frequently been criticized as irresponsible and environmentally damaging (Lamb and Dao 2017; Gong 2018). Growing demand for electricity in China and the fact that Myanmar is one of the most water rich counties in Asia 
(The World Commision of Dams 2000), have resulted in Myanmar being a "hot spot" for Chinese hydropower investments. These investments have been generally located in controversial and conflict prone regions (Kattelus et al. 2015).

In addition to its rich mineral, water and forest resources, Myanmar is also a strategic link between the South and Southeast Asia, which gives it high relevance in China's Belt and Road Initiative (BRI). Following the old Chinese saying: "To be rich, build roads first," in 2013 Beijing announced its Belt and Road Initiative (BRI). BRI is possibly the largest infrastructure project in history, with projects spanning almost 80 countries (Hillman 2018). The core of the BRI involves establishment of six economic corridors which consist of networks of highways, railways, ports, harbor- and airport-related infrastructure (Yu 2017). This massive development initiative poses significant risks for biodiversity (e.g., direct destruction of habitats and habitat fragmentation due to infrastructure development and extraction of resources, as well as increasing access for wildlife trafficking and roadkill; Hughes 2019). Given Myanmar's status as a biodiversity hotspot and its strategic position in China's BRI, it is particularly exposed to these risks.

It is important to evaluate the potential impact of development in Myanmar before the projects take place and provide decision-makers with knowledge of impacts and the potential for modifying development plans to minimize adverse impacts while meeting development goals (e.g., Kaszta et al. 2019). Research studies that rigorously evaluate the effects of realistic development scenarios on ecosystems and populations are still rare. One recent example is Kaszta et al. (2019), who quantified and mapped potential impacts of the Sabah (Malaysia) Structure Plan on population of Sunda clouded leopard (Neofelis diardi). Another recent example is the study of Thatte et al. (2018) simulating future landscape changes and its impact on tigers in India based on genetic data. These studies were able to use landscape modelling tools to evaluate a large number of realistic, spatially explicit development and conservation scenarios, and predict their impacts of population viability of their focal species.

The goal of this work was to assess the impact of several major investments that are likely to be implemented in Myanmar, including the Chinese Belt and Road Initiative (Silk road and Pipeline Railroad),
India-Myanmar-Thailand Trilateral Highway, 53 hydropower dam projects and emerging growth and transport centres, on the population size, genetic diversity and connectivity of mainland clouded leopard (Neofelis nebulosa), which is as an indicator species of forest habitats in Southeast Asia (Macdonald et al. 2019). We selected clouded leopards for this study not only because of their increasing importance as a top predator in SE Asia, following the rapid disappearance of tigers and common leopards, but also because their relative broad distribution in forested landscapes, combined with their charisma, makes them powerful ambassador species (Macdonald et al. 2017). In this paper we explore the balance between national development plans and the status of clouded leopards, but in this context, while a priority in themselves, clouded leopards are best thought of as an indicator and umbrella for forest biodiversity in the region (see also Macdonald et al. 2019).

We combined several recently developed approaches from landscape ecology and landscape genetics (e.g., Kaszta et al. 2019), and a large empirical dataset on clouded leopard occurrences across its entire range (Macdonald et al. 2019), to evaluate potential effects of development projects on Myanmar's clouded leopard population and its habitats. Our ultimate purpose is to use these projections as a basis for exploring policy-relevant options to balance the imperatives of economic development and biodiversity conservation. Furthermore, we offer this analysis as an illustration of an evidence-based approach that is generally applicable to the integrated planning of development and conservation, and as such represents a tool-kit adaptable to the needs of governments and planners across this region and in other parts of the world.

\section{Methods}

\section{Development scenarios}

We analysed five major existing or planned development scenarios: (1) India-Myanmar-Thailand Trilateral Highway; (2) BRI Silk Road; (3) BRI Pipeline Railroad; (4) construction of 53 hydropower dams; (5) 126 emerging growth and transport centres, individually and combined. 
The India-Myanmar-Thailand Trilateral Highway is a project under the Mekong- Ganga Cooperation Initiative which began in 2005 and will connect India with the ASEAN (Association of Southeast Asian Nations) via a $1360 \mathrm{~km}$ highway running from Moreh (India) via Mandalay (Myanmar) to Mae Sot in Thailand (Kimura and Umezaki 2011; De and Ray 2013). Various segments of the highway are already completed, and construction is ongoing. The Silk Road is a key part of the BRI and will connect Kolkata through Bangladesh and Myanmar to Kunming in China by a railway/highway corridor of about $3000 \mathrm{~km}$ in length. The Pipeline Railroad (The Kunming-Kyaukphyu high speed railway project) is also an element of the BRI. It will follow the existing oil and gas pipeline connecting Kyaukphyu port on Andaman See in Myanmar with Kunming in China.

We also investigated the impact of 53 planned reservoirs linked to hydropower plants. This included the controversial and, as of 2017, suspended Myitsone Dam on the Irawaddy River, the Mong Ton (or Tasang) dam on the Salween river (the tallest in SE Asia), as well as the Tamanthi dam on Chindwin River, near the Tamanthi Wildlife Reserve (one of our focal study sites, Naing et al. 2017). We emphasise that the effect of dams measured in this study included only the impact of the water reservoirs as habitat loss or barriers and did not include projection of associated transportation networks or other landscape changes associated with these dams, and as such is a partial and highly conservative evaluation of the ecological effects of these dams.

The scenario which projects the impacts of urban growth and transport centres was based on the best existing projection of 28 economic growth centres, including national, secondary, regional, and other centres with different growth potential (ICEM). This scenario also included 98 transport centres, including border trade areas, international airports and seaports, industrial zones, tourist development zones and densely populated areas (Table 1). Due to the lack of existing accurate spatial layers for the Indian Highway, Silk Road and Pipeline Railroad, we digitalized those scenarios based on the sources in Table 1 .

Landscape resistance surface

The resistance surface used for modeling was based on Macdonald et al. (2019), who produced a scale- optimized (sensu McGarigal et al. 2016) habitat suitability model for clouded leopard from 2948 camera stations set within 45 sampling grids. The surveys were carried out between 2008 and 2016 in nine countries, spanning the entire range of $N$. nebulosa throughout Southeast Asia. We tested relationships between 46 biologically informative variables at eight spatial scales $(250 \mathrm{~m}-32 \mathrm{~km})$ clouded leopard detection in this large camera trap database. This was done using a scale-optimized generalized linear mixed-effect model (GLMM) with a Poisson link, including number of active trap nights for each camera station as a fixed effect and sampling site nested within country as random effect. The final model comprised ten variables: camera effort, percentage of closed forest, percentage of forest cover, mean compound topographic index (CTI), mean annual precipitation, percentage of mosaic habitat, slope position (mean and standard deviation), correlation length (i.e. extent) of protected areas and grassland/shrubland habitats (Macdonald et al. 2019). This model indicated that clouded leopard occurrence is highly associated with areas with extensive forest cover, protected areas, high precipitation and upland or ridge locations.

Some studies have shown that habitat suitability based on occurrence data might not be the best surrogate for resistance to movement (e.g., Wasserman et al. 2010; Zeller et al. 2018), especially when accounting for dispersal and mating movement (Elliot et al. 2014a; Keeley et al. 2017). However, MateoSánchez et al. (2015a, b) and Zeller et al. (2018) found that, in the absence of data on movement behaviour or genetic structure themselves, habitat selection can be a useful surrogate for resistance to movement. Given there is no currently existing movement or genetic data on clouded leopard in Myanmar, we chose to use habitat selection as a proxy [sensu Mateo-Sanchez et al. (2015a, b), Zeller et al. (2018)]. Following Mateo-Sánchez et al. (2015a, b) and Keeley et al. (2016) who showed that a negative exponential function best describes the relationship between habitat suitability and resistance values, we transformed suitability to resistance using Eq. (1).

EQ1 $\operatorname{Exp}(-1 *$ Habitat suitability/1.5) +0.78 
Table 1 Method of data acquisition and source for each of the development scenarios

\begin{tabular}{|c|c|c|}
\hline $\begin{array}{l}\text { Development } \\
\text { scenario }\end{array}$ & Data acquisition & Source \\
\hline $\begin{array}{l}\text { India-Myanmar- } \\
\text { Thailand } \\
\text { Trilateral } \\
\text { Highway }\end{array}$ & Digitalization & $\begin{array}{l}\text { Existing segments: } \\
\text { - Myanmar road network maps corrected by Google } \\
\text { Imagery } \\
\text { Planned segments: } \\
\text { - Ministry of Extenral Affairs of Government of } \\
\text { India } \\
\text { - List of connected cities: De and Ray } 2013\end{array}$ \\
\hline Silk Road & Digitalization & $\begin{array}{l}\text { - The Financial Express (https://thefinancialexpress. } \\
\text { com.bd/views/kunming-initiative-and-sub-regional- } \\
\text { free-trade-1505490137) } \\
\text { - The Belt \& Road Center (http://beltandroadcenter. } \\
\text { org) } \\
\text { - United Nations Trans-Asian Railway Network Map } \\
\text { (https://www.unescap.org/sites/default/files/TAR } \\
\text { map_1Nov2016.pdf) }\end{array}$ \\
\hline Pipeline Railway & Digitalization & $\begin{array}{l}\text { - Reconnecting Asia (https://reconnectingasia.csis. } \\
\text { org) } \\
\text { - https://www.mapim.org/single-post/2018/01/19/ } \\
\text { Kepentingan-Geopolitik-Wilayah-Arakan-Nasib- } \\
\text { Rohingya }\end{array}$ \\
\hline $\begin{array}{l}\text { Dams (planned } \\
\text { hydropower } \\
\text { projects) }\end{array}$ & $\begin{array}{l}\text { Existing shapefile layer of dam reservoirs associated } \\
\text { with hydropowers }\end{array}$ & $\begin{array}{l}\text { ICEM-International Centre for Environmental } \\
\text { Management }\end{array}$ \\
\hline Economic zones & $\begin{array}{l}\text { (1) Concentrated decentralization shapefile (economic } \\
\text { growth canters of varying potential) } \\
\text { (2) Transport plan (town and cities with varying } \\
\text { potential for transport, e.g. industry areas, tourist } \\
\text { zones, boarder trade areas, densely populated zones) }\end{array}$ & $\begin{array}{l}\text { ICEM-International Centre for Environmental } \\
\text { Management }\end{array}$ \\
\hline
\end{tabular}

The final resistance layer was produced at a $250 \mathrm{~m}$ pixel size across Myanmar plus a buffer of $200 \mathrm{~km}$ and had values spanning between 1 and 198 .

The empirical habitat suitability model developed by Macdonald et al. (2019) did not account for the impact of roads, railways, water, or urban areas. These landscape features are widely known to affect movement and connectivity (e.g., Cushman and Lewis 2010; Elliot et al. 2014b). Therefore, we added a 2-pixel wide layer representing existing roads and railroad (layer provided by the International Centre for Environmental Management (ICEM)) to the resistance surface, and assigned additional resistance cost to these cells based on expert opinion depending on the type of road and railroad (additional resistance of three cost units for major roads/railroads, two for secondary, one for tertiary). Rivers and existing water reservoirs (provided by ICEM), including those linked to hydropower dams, were considered highly resistant landscape elements to clouded leopard movement (following Hearn et al. 2018), and we assigned a resistance of 50 to these features. These additional elements were added to the pixel costs of the original resistance surface.

To explore of the impacts of future development scenarios we prepared separate resistance surfaces for each scenario by adding pixel cost associated with the projected development to the base resistance surface described above. For the Indian Highway, Silk Road and Pipeline Railroad scenarios, based on expert opinion, we assigned an additional resistance value of five to the pixels projected to experience development in those scenarios. To account for the likely diffuse 
effect of these massive communication arteries on the clouded leopard population, we added a logarithmically decreasing function of resistance, which decreased a resistance value of five assigned to the highway/railway itself, to one at a distance of $20 \mathrm{~km}$ from the structure. In the scenario investigating the impacts of 53 new dams, we assigned a resistance of 50 to the pixels projected to be flooded by the reservoirs created by these new dams. Furthermore, based on expert opinion, we assigned varying resistance values to different types of economic growth and transport centres (Table 2). We also simulated the diffusive effect of the growth/transport centres, which varied depending on the type of economic zone/transport centre (Table 2). To do that, similar to how we modelled the diffusive effect of roads, we applied a logarithmically decreasing function of resistance, with resistance values decreasing from the maximum assigned to that growth/transport centre to resistance equal 1 at a given distance determined in Table 2 .

\section{Source points}

For robust prediction of actual patterns of connectivity across populations it is essential that source points reflect the actual distribution and density of the target population (Cushman et al. 2016). We distributed 10,000 points across SE Asia (reflecting the estimated population size of clouded leopard (IUCN Red List 2017) with a density proportional to habitat suitability for clouded leopard (Macdonald et al. 2019). This was done in four steps. First, we rescaled the habitat suitability layer between 0 and 1 . Second, we created a uniform random raster (values between 0 to 1 ). Third, we subtracted the random raster from the habitat suitability layer. Positive values of the resulting layer reflected potential occurrences probabilistically distributed based on habitat suitability. Fourth, we randomly selected 10,000 points from the positive values of the difference raster. To provide spatial replicates for population and genetic simulation modelling we generated ten different sets of source points, each using a different uniform random raster. Finally, we clipped the points to the area of Myanmar's borders plus a buffer of $200 \mathrm{~km}$. This resulted in an average number of source points in the study area (Myanmar + buffer) of 4430, with maximum 4446 and minimum 4186.

Connectivity analysis

All connectivity analyses were performed using UNICOR software Landguth et al. 2012). To identify the main pattern of synoptic connectivity and core habitat areas for clouded leopard we used cumulative resistant kernel connectivity modelling Compton et al. 2007). This method maps the most cost-effective movement routes from a source cell to every other cell in the landscape given a maximum dispersal costdistance. The cumulative resistant kernel surface reflects the incidence function of rate of movement through each cell in the landscape (Kaszta et al. 2018) and it is calculated by summing the least-cost kernels from all source points (Compton et al. 2007).

The factorial least-cost path method complements cumulative resistant kernels by defining the network of linkages among all source points following the least-cost routes across the landscape, up to a specified
Table 2 Resistance values assigned to different types of economic zones

\begin{tabular}{lll}
\hline Economic zone & Max resistance & Radius of influence [KM] \\
\hline Growth centres & & \\
National Economic Growth Centre & 15 & 40 \\
Secondary Regional Growth Centre & 10 & 20 \\
Other towns with different growth potentials & 5 & 10 \\
Transport centres & & \\
Border trade area & 15 & 40 \\
Densely populated area & 15 & 40 \\
Industry zone & 20 & 50 \\
International airport & 15 & 40 \\
International seas port & 20 & 50 \\
Tourism attraction zone & 10 & 20 \\
\hline
\end{tabular}


dispersal cost threshold. Factorial least-cost paths are computed by summing the least-cost costs paths between all pairs of points (Cushman et al. 2013a). The density of these least-cost path networks is highly related to betweenness centrality (Mateo-Sánchez et al. 2014) and has been shown to be highly predictive of actual routes of animal movement across landscapes (Cushman et al. 2014).

Unlike many other connectivity modelling approaches, both cumulative resistant kernels and factorial least-cost paths, as implemented in UNICOR software, account for species dispersal abilities, which is essential for accurate prediction of landscape-scale patterns of connectivity (Cushman et al. 2013b). Dispersal distances are not well known for clouded leopards; however, a number of studies have found relationships between maximum dispersal distances and home range size (Bowman et al. 2002; Whitmee and Orme 2013). With the average home range of $N$. nebulosa varying between 23 and $45 \mathrm{~km}^{2}$, it is estimated that clouded leopard may disperse up to $160-252 \mathrm{~km}$ in highly suitable habitat (Macdonald et al. 2018). Several previous studies have simulated clouded leopard dispersal with the methods we employ here (Hearn et al. 2019; Macdonald et al. 2018). To maximize comparability with these previous studies and because they chose dispersal thresholds based on the best available biological information, we adopted the same dispersal threshold of 250,000 cost units for cumulative resistant kernel analysis. This dispersal threshold represents a cumulative cost per map unit (in this case-a meter) of an animal traversing a distance of $250 \mathrm{~km}$ through a uniform landscape of resistance equal 1 . We chose a cost unit threshold value of $1,250,000$ for least-cost paths to model long-distance connections beyond the extent of locally connected populations to prioritize conservation of stepping stones and linkage areas that are beyond the dispersal ability of most individual animals but are important for long-term connectivity of metapopulations (e.g., Cushman et al. 2018; Elliot et al. 2014b).

We ran cumulative resistant kernels and least-cost paths for the base scenario (reflecting the current situation of connectivity), for each of the five development scenarios, and for the scenario combining the developments into one resistance layer. To measure the synoptic change in landscape connectivity in each scenario we subtracted the base cumulative kernel and factorial least-cost path surfaces from the cumulative kernel and factorial least-cost path surfaces produced by each of the development scenarios and calculated the mean of this difference. Furthermore, to compare the total change in connectivity among scenarios we calculated the difference in the sum of kernel values between each development scenario and the base scenario.

Fragmentation analysis

To investigate the effect of the development scenarios on the extent, pattern and fragmentation of clouded leopard habitat and its connectivity we first extracted core areas, defined as areas of the highest predicted movement density (e.g., greater than the median value of the cumulative resistant kernel surface, which was 10). We then calculated several landscape metrics using FRAGSTATS software (McGarigal et al. 2012), including percent of landscape (PLAND), largest patch index (LPI), and correlation length (GYRATE_AM). These metrics have frequently been used in assessments of connectivity (e.g. Cushman et al. 2016; Kaszta et al. 2019) and have been shown to be highly related to genetic differentiation (Cushman et al. 2013c). PLAND represents the extent of the landscape covered by connected habitat, LPI is the percentage of the landscape covered by the largest single patch of connected habitat, and GYRATE_AM represents the expected distance from a random location within a connected habitat to the edge of this habitat, moving in a random direction and in a straight line. We then calculated the difference in these metrics between each development scenario and the base scenario.

Sensitivity analysis

We performed a set of sensitivity analyses to assess how sensitive the results of cumulative resistant kernels and factorial least-cost paths are to parametrization of the resistance values. This was done by creating resistance layers with halved and doubled initial resistance value for each landscape element (following Kaszta et al. 2019). These layers were then used to calculate cumulative resistant kernels and factorial least cost paths. We then calculated the correlation and absolute average difference across all three variations of resistance (following Hearn et al. 2019). 
Simulating population dynamics and genetic diversity

We used CDPOP to simulate spatial patterns of mating and dispersal as a function of suitable habitat and dispersal cost. CDPOP is an individual-based, spatially explicit cost-distance population genetics program (Landguth and Cushman 2010) that simulates mating, dispersal and mortality as functions of landscape resistance and mortality risk. We parametrized the model with standard simulation parameters (e.g., Cushman and Landguth 2010; Landguth et al. 2010a, b; Hearn et al. 2019; Kaszta et al. 2019) presented in Table 3. We simulated gene flow for 200 generations to ensure spatial genetic equilibrium (Landguth et al. 2010a, b).

We also incorporated spatially heterogenous mortality risk, which can have large impacts on populations dynamics (e.g., Kaszta et al. 2019). The relationship between landscape elements (e.g., land cover types, roads and railroads) and risk of mortality for clouded leopard is unknown. However, it is likely associated with habitat quality and landscape resistance (e.g. Mateo-Sánchez et al. 2015b). We therefore used the resistance surface to derive surfaces of mortality risk for each of the landscape features. Roads and railways cause not only a risk of direct mortality trough road-kill, but they also provide human access to wild habitats, which increases risk of poaching and habitat loss and degradation. This effect was not included in the base resistance surface. Therefore, for the existing roads/railways we added additional mortality risk values, by including mortality risk that was proportional to the additional resistance associated with these features, logarithmically decreasing effect from a road/railway up to $20 \mathrm{~km}$. The major developments like the Indian Highway, Silk Road and Pipeline, and growth centres likely will produce much stronger risk of mortality; therefore the source points within the buffer of their diffusive effect (see Table 2) were removed, which reflects $100 \%$ mortality in proximity to these features. CDPOP requires that values of the mortality layer need to be between 1 and 100, thus mortality values exceeding 100 were saturated to 100 .

We tested for significant differences in simulated (based on 10 Monte Carlo simulations; Table 3) clouded leopard population size, allelic richness and heterozygosity across all scenarios using ANOVA and Tukey HSD in R (R Development Core Team 2012). Furthermore, to map spatial patterns in clouded leopard population density across Myanmar we applied the kernel point density function in ArcGIS 10.x (ESRI 2012). Additionally, to map allelic richness and heterozygosity we used Inverse Distance Weighting (IDW) interpolation (all as an average of 10 Monte Carlo replicates). To show the change in population size and populations dynamics we computed differences maps between each of the development scenarios and the base.

\section{Results}

\section{Current connectivity}

In the base scenario we can distinguish two large clouded leopard core habitat areas. One of them

Table 3 Input parameters for population dynamics simulations in CDPOP

\begin{tabular}{ll}
\hline Input parameters & Set-up \\
\hline Number of generations & 200, non-overlapping \\
Number of loci & 30 \\
Number of alleles per loci & 10 \\
Mutation rate & 0.0005 \\
Type of mating & Inverse square \\
Number of offsprings & Poisson probability draw of mean = 2 \\
Dispersal/movement choice & Dispersal probability function with maximum cost-weighted dispersal distance of 125 km \\
Number of Monte Carlo simulations & 10 \\
\hline
\end{tabular}


spreads over the northern and western parts of the country, covering the states of Rakhine and Kachin, as well as a large part of Sagaing, continuing into India (Fig. 1). The second core area is located in southern Myanmar, covering nearly all of Kayin, Mon and Tanintharyi states, and extending into the so-called Western Forest Complex in Thailand. Furthermore, in the eastern corner of the Myanmar (Shan state) lies a small portion of a large core area, which continues deep into Laos. In addition to these three important core areas, Myanmar also contains five smaller core areas (Fig. 1). The two largest core areas are connected by a network of corridors. These corridors also link the large core area which spreads into Laos (Fig. 1).

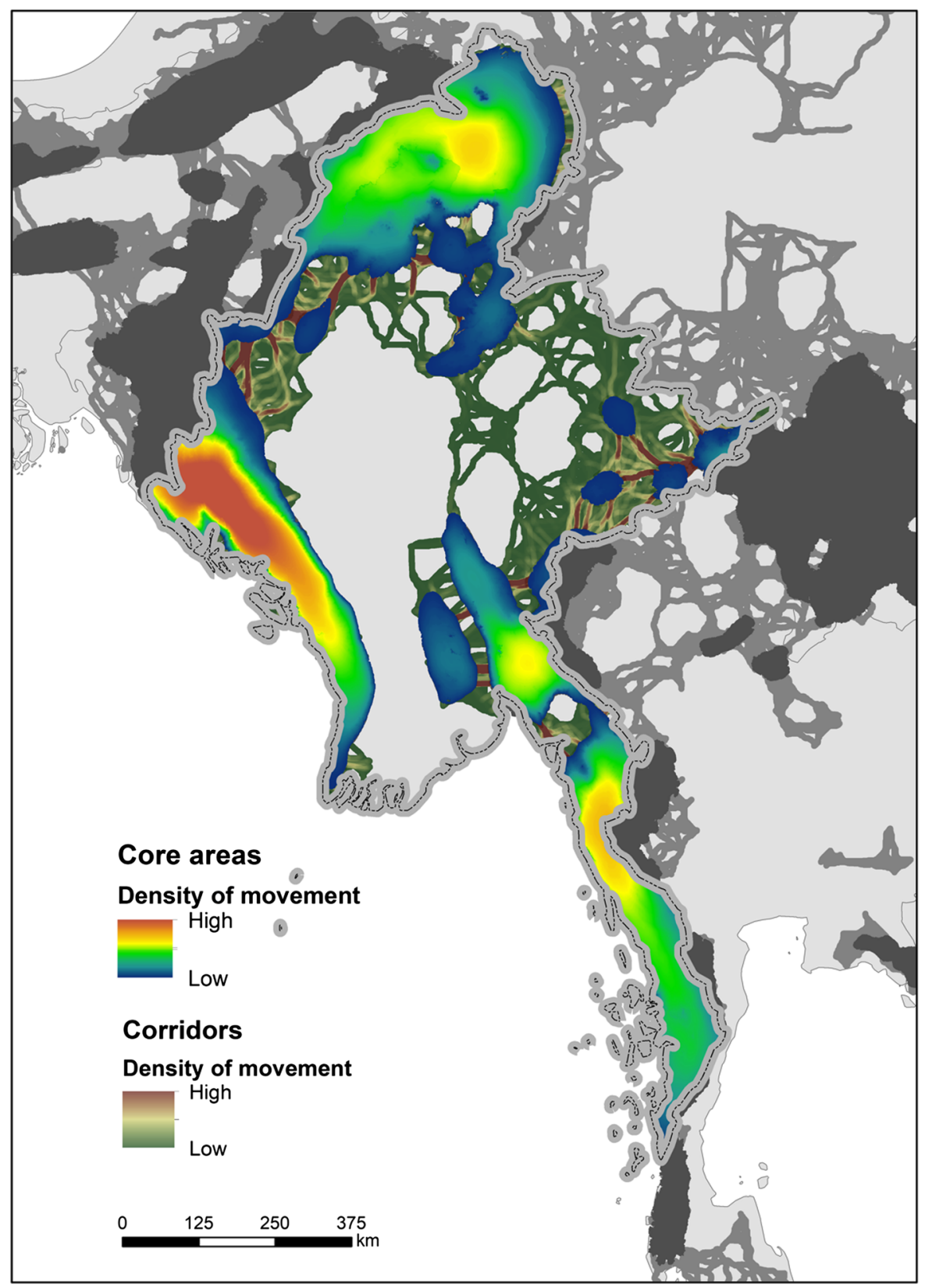

Fig. 1 Core areas as results of cumulative resistant kernels analysis and corridors from factorial least-cost paths in the base scenario 
Impact of developments on landscape connectivity

All development scenarios had negative effects on modelled connectivity but varied greatly in the magnitude and spatial location of their effects (Table 4, Figs. 2 and 3). Across all development scenarios, the growth of cities and transport centres resulted in the largest decrease in clouded leopard core habitat extent and largest increase in their fragmentation. For example, this scenario resulted in a $62 \%$ drop in core areas' correlation length and 52\% decrease in largest patch index, as well as more than a $23 \%$ decrease in the sum of kernel values (Table 4). This negative impact of urban and industrial economic zones affected the entirety of Myanmar, causing fragmentation of the biggest core areas (Fig. 2e) and decrease in connectivity in the entire corridor network, particularly in the already tenuous corridors linking the two largest core areas (Fig. 3e).

The Indian Highway was also predicted to have a large negative impact on connectivity, with a $50 \%$ decrease in correlation length and 39\% of largest patch index (Table 4). Our analysis predicted that development of the Indian Highway would lead to the fragmentation of the two biggest clouded leopard core areas in Myanmar (Fig. 2c). It also runs through the network of corridors linking the two core areas in southern Myanmar (Fig. 3c), threatening these critically important core habitats and the connectivity between them.

The Pipeline Railroad, although it did not have a large impact on core area connectivity (as measured by FRAGSTATS analysis of resistant kernels), would pass through the area of the highest predicted clouded leopard density of movement in one of the strongest core areas (Fig. 2a), causing a predicted $4 \%$ decrease in sum of kernel values (Table 4). Furthermore, the railroad decreased the strength of the vulnerable network of corridors linking the two largest core areas (Fig. 3a). These corridors are also significantly weakened by the development of dams in that area, in particular the controversial Mong Ton dam (Fig. 3d).

Implementing all the planned developments was predicted to have a very large impact on the clouded leopard core areas, decreasing their strength (sum of kernel values) by nearly $36 \%$ and their size (percentage of landscape) by more than 20\% (Table 4), affecting clouded leopard core habitats and corridors across the entire country (Figs. $2 \mathrm{f}$ and $3 \mathrm{f}$ ).

\section{Sensitivity analysis}

The sensitivity analysis showed that the results of cumulative resistant kernels and factorial least-cost paths for each of the scenarios are largely insensitive to the resistance value assigned to the investigated element of the landscape. Cumulative resistant kernels and factorial least-cost paths results for each of the scenarios across all tested resistance values were highly correlated (Pearson's correlation $\geq 0.95$ for cumulative kernels and $\geq 0.89$ for least-cost paths) and they exhibited very small absolute average difference (Tables S1 and S2).

Population dynamics and genetic diversity

The simulated mean clouded leopard population size after 200 generations for the base scenario decreased from the initial 4200 to around 3600 individuals, amounting to a $14 \%$ drop in population size without any additional developments (Fig. 4). All development scenarios resulted in projected additional

Table 4 Percentage difference in sum of kernel values and several landscape metrics related to clouded leopard core areas connectiveness between each development scenario and the base scenario

\begin{tabular}{lcccc}
\hline Scenario & Kernel sum $(\%)$ & Percentage of landscape $(\%)$ & Largest Patch Index $(\%)$ & Correlation length $(\%)$ \\
\hline Dams & -2.33 & -0.43 & -0.18 & -0.22 \\
Growth and transport centers & -23.56 & -16.63 & -52 & -62 \\
Pipeline Railroad & -3.93 & -0.30 & -0.45 & -0.12 \\
Silk Road & -0.39 & -1.24 & -39 & -37 \\
Indian Highway & -2.27 & -3.48 & -39 & -50 \\
Full development & -35.7 & -20.4 & -53 & -61 \\
\hline
\end{tabular}




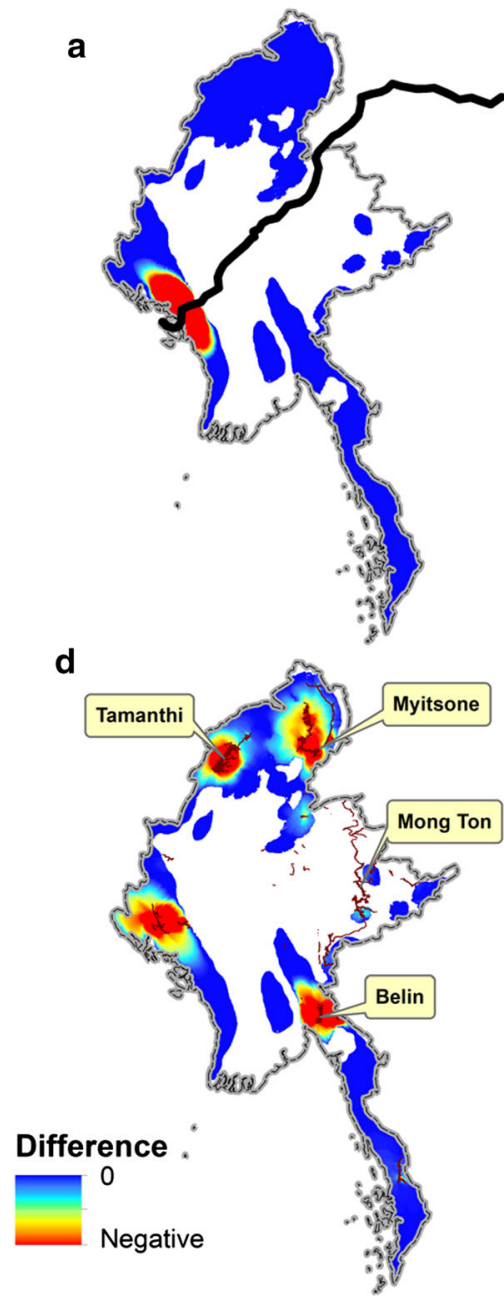

Fig. 2 Predicted change in clouded leopard movement intensity within core areas, calculated as the difference in cumulative resistant kernels surfaces between each of the development

declines in simulated population size. These changes were highly statistically significant for growth of cities and transport centres (Table 5, Fig. 4). The latter scenario showed the largest, nearly $25 \%$, decrease in clouded leopard population size (Table 5, Fig. 4). Integrating all scenarios resulted in a simulated population decline of more than 29\% (Table 5, Fig. 4). All scenarios also produced declines in simulated genetic heterozygosity. However, these differences were statistically significant only for the Pipeline Railroad, potential economic zones and the integrated scenario, which produced decreases in simulated heterozygosity of 4, 13 and $19 \%$, respectively (Table 5, Fig. 4). Allelic richness also declined

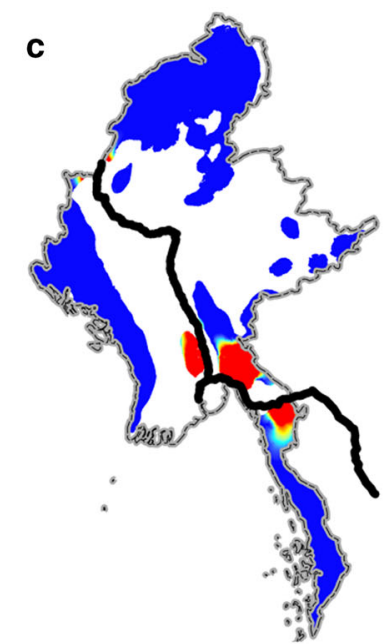

f

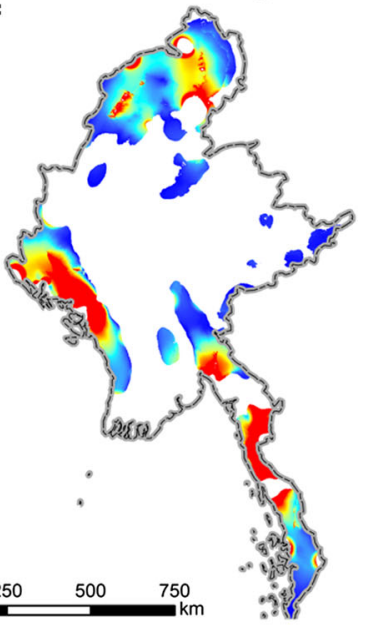

scenarios and the base scenario. a Pipeline, b Silk Road, c Indian Highway, d Dams, e Cities, d Integrated

across all scenarios compared to the base scenario, but this difference was statistically significant only for the integrated scenario (drop by 1.9; Table 5, Fig. 4).

The spatial pattern of the difference in population density between the base and each development scenario revealed strong negative effects that were rather localized to regions surrounding the sites of each scenario's developments (Fig. 5). Allelic richness and heterozygosity showed the same spatial pattern with much broader negative effects than just around the site of a development (Fig. 6). Across all scenarios involving roads and railroads, the Pipeline Railroad showed the strongest decrease in genetic diversity, particularly affecting the important core 


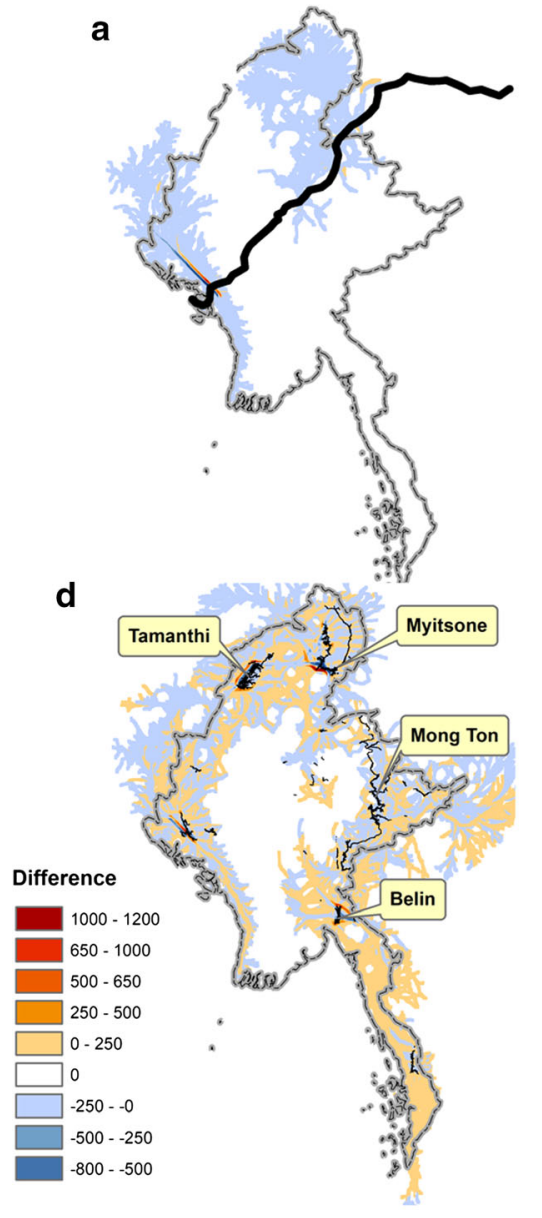

Fig. 3 Impact of developments on clouded leopard corridors calculated as difference in factorial least-cost paths between each of the development scenarios and the base scenario (blue

population in Rakhine State (Fig. 6a). Growth of cities and transport centres produced large simulated decreases in genetic diversity across nearly the entirety of Myanmar (Fig. 6e), and this effect increased when integrating all the developments (Fig. 6f).

\section{Discussion}

Myanmar's forests are a biodiversity jewel in Southeast Asia, and support hundreds of globally threatened species (Wildlife Conservation Society (WCS) 2012). Furthermore, recent analysis reveals that together, Myanmar and Laos encompass the most significant source population of clouded leopards in Indo-China
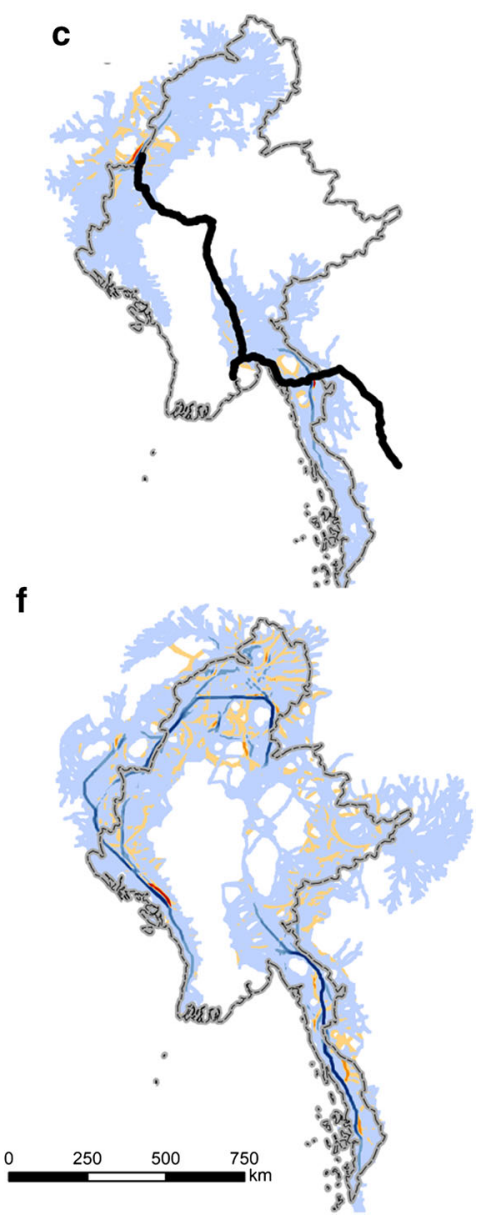

colour indicates decrease in corridor use, colours from orange to red indicate increase in corridor use. a Pipeline, b Silk Road, c Indian Highway, d Dams, e Cities, d Integrated

and thus, probably, in the world (Kaszta et al. in press). The forests crucial to these clouded leopards are also essential habitat for a wide array of biodiversity for which these leopards are umbrella and ambassador species (Macdonald et al. 2017). However, the IndoBurma biodiversity hotspot is also one of the most globally threatened, and due to overexploitation and continuing forest loss, it is likely to lose a large number of its plants and vertebrates in the near future (Rao et al. 2013; Hughes 2017). With Myanmar being the second largest country in Southeast Asia and the largest part of the Indo-Burma hotspot, the county's recent political and economic transition has important implications for Myanmar's valuable and vulnerable natural resources. The end of decades of political and economic isolation has opened Myanmar to immense 
Fig. 4 Simulated clouded leopard population size (a), allelic richness (b) and heterozygosity (c) for each scenario and after 200 generations based on 10 Monte Carlo simulations

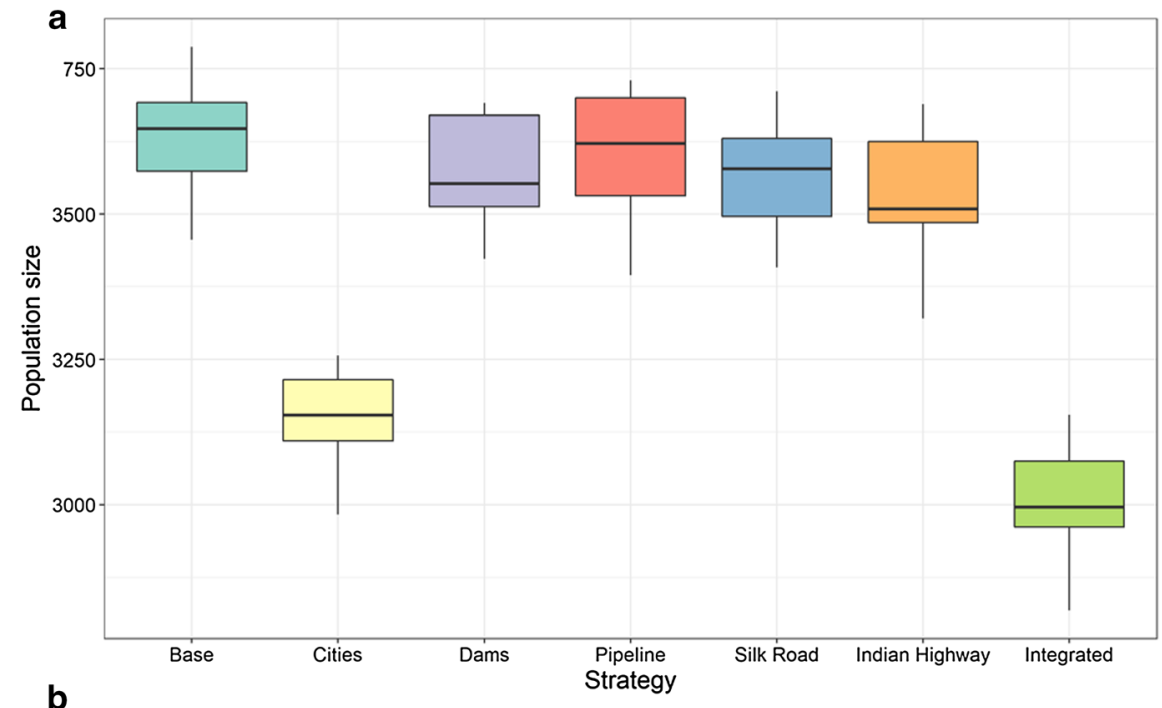

b
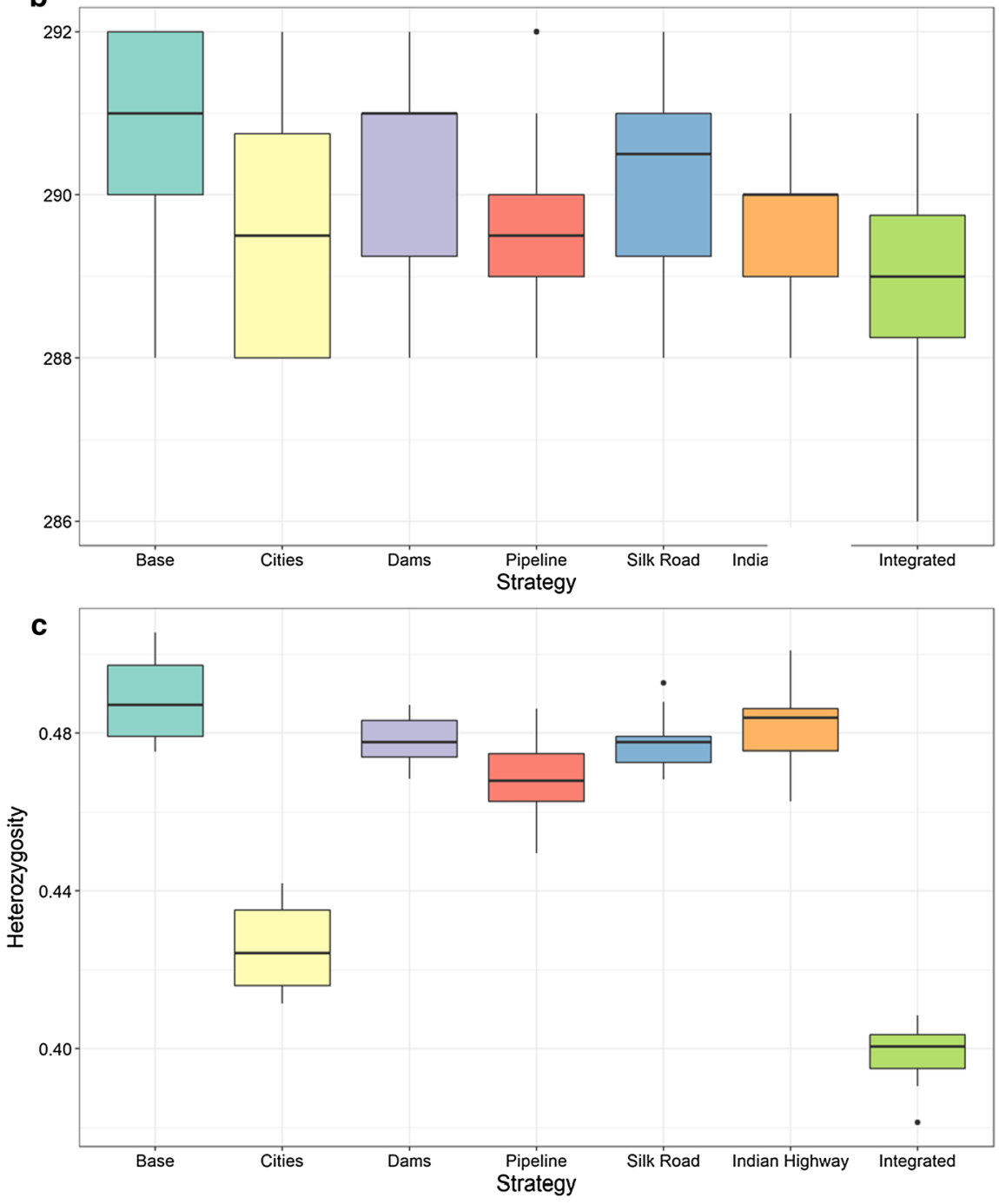
Table 5 Results of Tukey HSD test for significance of differences in population size, alleles and heterozygosity between scenarios
Bold values indicated $p<$ 0.05

\begin{tabular}{|c|c|c|c|c|c|c|}
\hline \multirow[t]{2}{*}{ Strategy } & \multicolumn{2}{|c|}{ Population size } & \multicolumn{2}{|l|}{ Alleles } & \multicolumn{2}{|c|}{ Heterozygosity } \\
\hline & Difference & $\mathrm{P}$ & Difference & $\mathrm{P}$ & Difference & $\mathrm{P}$ \\
\hline Cities-Base & -488 & 0.000 & -1.2 & 0.444 & -0.062 & 0.000 \\
\hline Dams-Base & -57 & 0.870 & -0.4 & 0.994 & -0.010 & 0.249 \\
\hline Indian Highway-Base & -94 & 0.374 & -1.1 & 0.549 & -0.006 & 0.759 \\
\hline Integrated-Base & -629 & 0.000 & -1.9 & 0.041 & -0.090 & 0.000 \\
\hline Pipeline-Base & -26 & 0.997 & -1 & 0.656 & $-\mathbf{0 . 0 2 0}$ & 0.001 \\
\hline Silk Road-Base & -64 & 0.789 & -0.4 & 0.994 & -0.011 & 0.193 \\
\hline Dams-Cities & 431 & 0.000 & 0.8 & 0.843 & 0.052 & 0.000 \\
\hline Indian Highway-Cities & 394 & 0.000 & 0.1 & 1.000 & 0.056 & 0.000 \\
\hline Integrated-Cities & -141 & 0.040 & -0.7 & 0.910 & -0.027 & 0.000 \\
\hline Pipeline-Cities & 462 & 0.000 & 0.2 & 1.000 & 0.043 & 0.000 \\
\hline Silk Road-Cities & 424 & 0.000 & 0.8 & 0.843 & 0.052 & 0.000 \\
\hline Indian Highway-Dams & -38 & 0.981 & -0.7 & 0.910 & 0.004 & 0.978 \\
\hline Integrated-Dams & -573 & 0.000 & -1.5 & 0.191 & -0.080 & 0.000 \\
\hline Pipeline-Dams & 30 & 0.994 & -0.6 & 0.955 & -0.010 & 0.304 \\
\hline Silk Road-Dams & -8 & 1.000 & 0 & 1.000 & -0.001 & 1.000 \\
\hline Integrated-Indian Highway & $-\mathbf{5 3 5}$ & 0.000 & -0.8 & 0.843 & $-\mathbf{0 . 0 8 3}$ & 0.000 \\
\hline Pipeline-Indian Highway & 68 & 0.742 & 0.1 & 1.000 & -0.013 & 0.048 \\
\hline Silk Road-Indian Highway & 30 & 0.994 & 0.7 & 0.910 & -0.004 & 0.956 \\
\hline Pipeline-Integrated & 603 & 0.000 & 0.9 & 0.757 & 0.070 & 0.000 \\
\hline Silk Road-Integrated & 565 & 0.000 & 1.5 & 0.191 & 0.079 & 0.000 \\
\hline Silk Road-Pipeline & -38 & 0.980 & 0.6 & 0.955 & 0.009 & 0.377 \\
\hline
\end{tabular}

foreign investment in development and infrastructure projects. This combination of development pressure and the country's weak environmental laws and poor enforcement capacity makes it urgent to conduct a comprehensive evaluation of the impacts of realistic alternative development scenarios to provide information to help government decision makers balance the trade-offs between development and conservation.

The work presented here is the first extensive attempt to evaluate the ecological impacts of major ongoing or planned developments in Myanmar, including those linked to the controversial Chinese Belt and Road Initiative. We applied methods from landscape ecology and landscape genetics, built on one of the most extensive sets of empirical data collected to date on Asian wildlife occurrence, to measure and map the effects of development on habitat connectivity, population size and genetic diversity of clouded leopard-a forest indicator with high capacity to serve as a conservation umbrella for other felids (Dickman et al. 2015). Clouded leopard can be a potentially useful focal species for optimizing the allocation of limited resources for biodiversity conservation in Myanmar (Macdonald et al. 2017), and also to serve as a "miner's canary" to alert policymakers to the consequences for wider biodiversity of forest loss and degradation.

Our results suggested that the current population size of clouded leopard in Myanmar may be above the long-term carrying capacity of the remaining habitat. Even without additional developments our simulations predicted a $14 \%$ drop in the species' population size. We hypothesize that this is a lag effect, the current population having not yet equilibrated to recent habitat losses. However, when all the scenarios considered in this study are simulated jointly (53 dams, Pipeline Railway, Silk Road, Indian Highway, creation of new economic zones), the impacts are predicted to be much worse, with an additional $36 \%$ loss of clouded leopard core dispersal areas and $29 \%$ decline of the species population size, as well as severing most of the important corridors linking core population areas. These developments are also predicted to substantially reduce the genetic diversity of the clouded leopard 
a
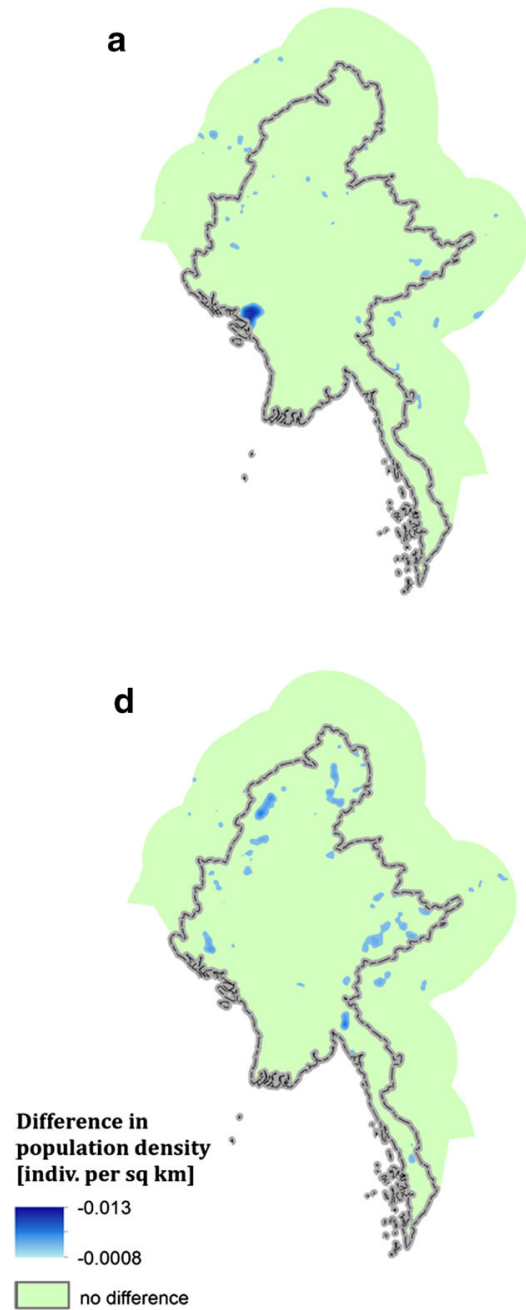

b

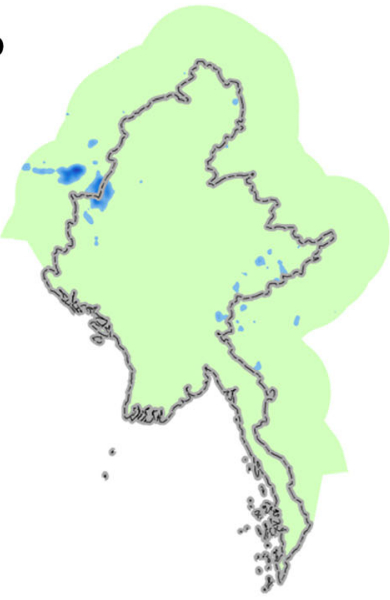

e

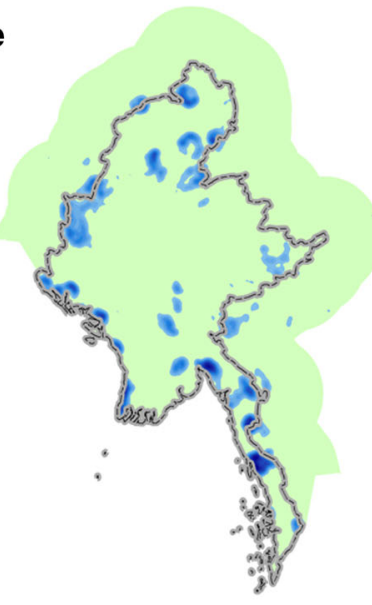

C

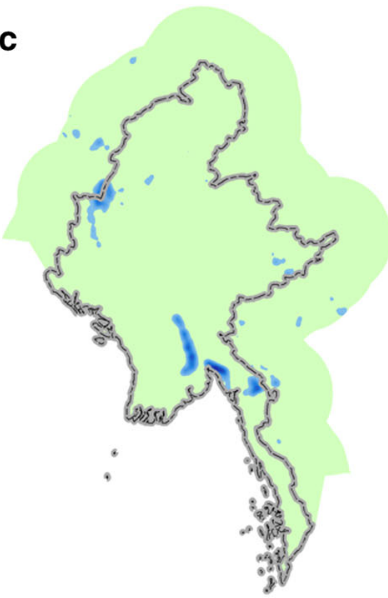

f

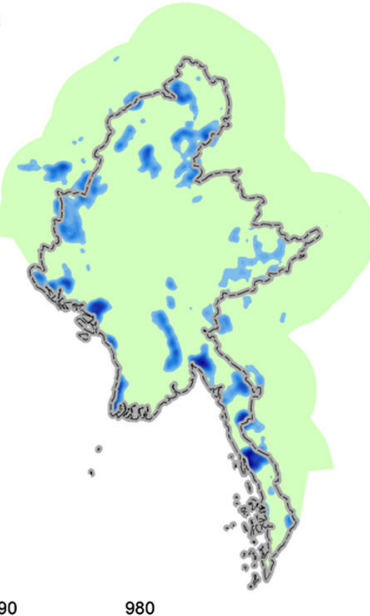

Fig. 5 Impact of each development on simulated clouded leopard population density in 200 generations calculated as a difference between a development scenario and the base scenario. a Pipeline, b Silk Road, c Indian Highway, d Dams, e Cities, d Integrated

population, with significant drops in heterozygosity and allelic richness. This may reduce the population's evolutionary capacity (Noël et al. 2007), and ultimately lead to inbreeding depression (Van Noordwijk 1994), creating an extinction vortex (Frankham 2005). The negative impact of the combined development scenario is predicted to affect the clouded leopard population across Myanmar, causing fragmentation of the two largest clouded leopard core areas, which are the most important clouded leopard core areas in all Southeast Asia (Kaszta et al. in press; Macdonald et al. 2019). Furthermore, our results showed that the combined scenario massively impacts the networks of corridors that link these core areas, significantly decreasing probability of clouded leopard dispersal, and in the longer term potentially leading to permanent disconnection of these subpopulation fragments.

While each of the simulated development projects had negative effects on clouded leopard dispersal habitats, corridors, population dynamics and genetic diversity, development of economic zones, linked to new emerging growth and transportation centres, had substantially the highest impact, with a projected $24 \%$ decrease in clouded leopard population connectivity and a $25 \%$ drop in population size. Establishment of economic zones was also predicted to break up the two largest core areas into smaller and isolated fragments, as well as weakening the corridors linking these core areas. The largest effect can be observed in the area of Mawlamyine (Mon State) and in Dawai (Tanintharyi 
a
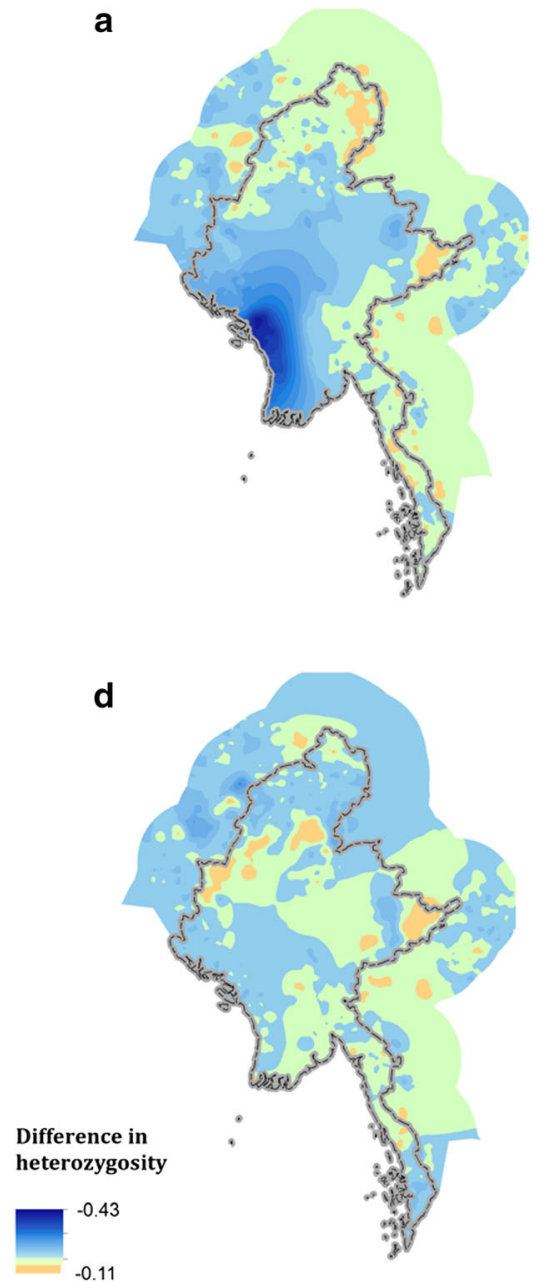

Fig. 6 Impact of each development on simulated heterozygosity of clouded leopard population inn 200 generations calculated as a difference between a development scenario and the base

Region), which are main trading centres and seaports in southern Myanmar, and also form a base for future tourist expansion along the Andaman Sea cost. This impact, combined with the effect of the border trade areas with Thailand around Myawady (Kayin State) and Simbyudaing (Tanintharyi Region), if not mitigated, may in the future cause substantial reduction in the size, quality and connectivity of Myanmar's second largest clouded leopard core dispersal area. This entire area is also affected by ongoing armed ethnic conflict, which complicates efforts to proactively implement landscape management and conservation plans. Another vulnerable area, which is part of
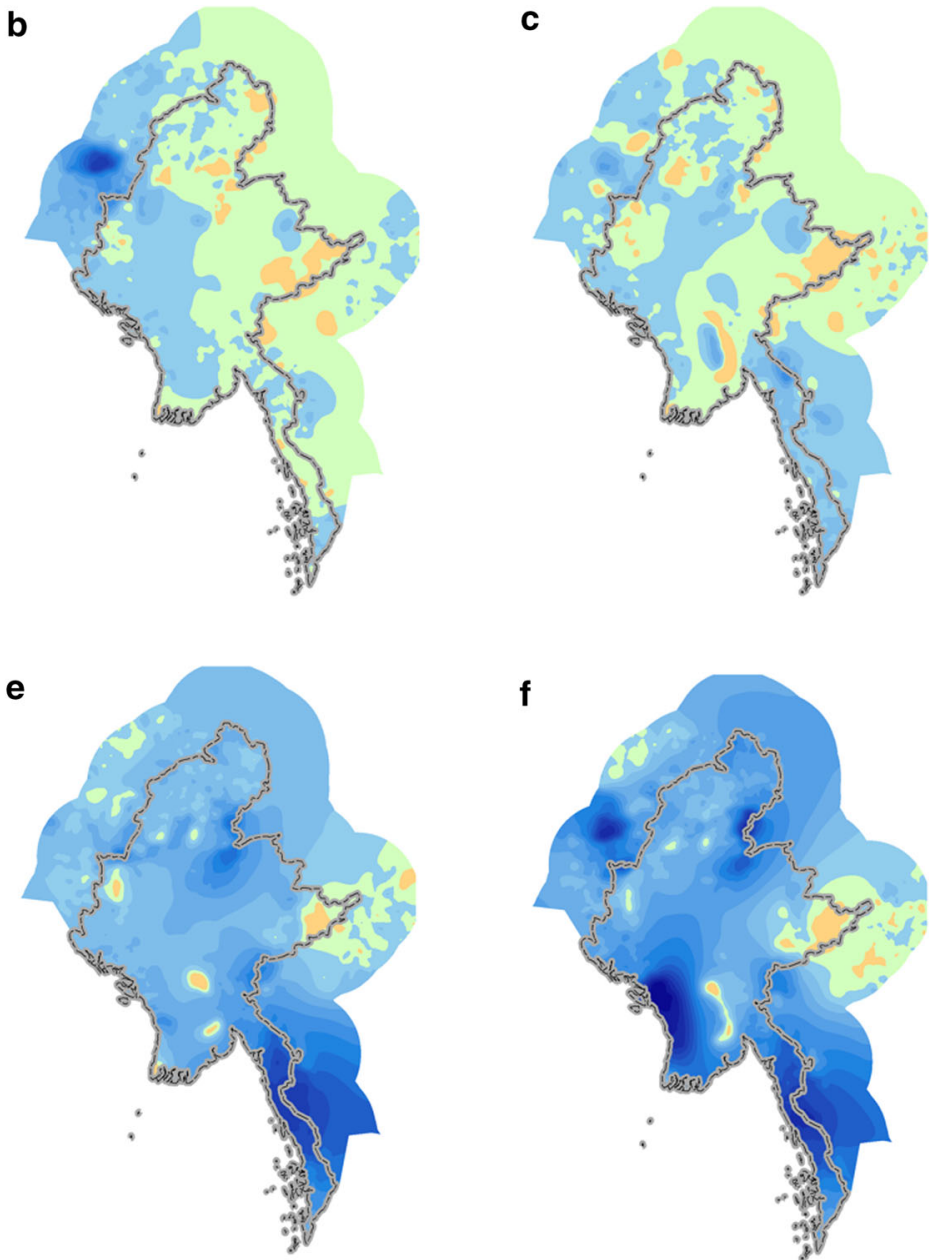

f
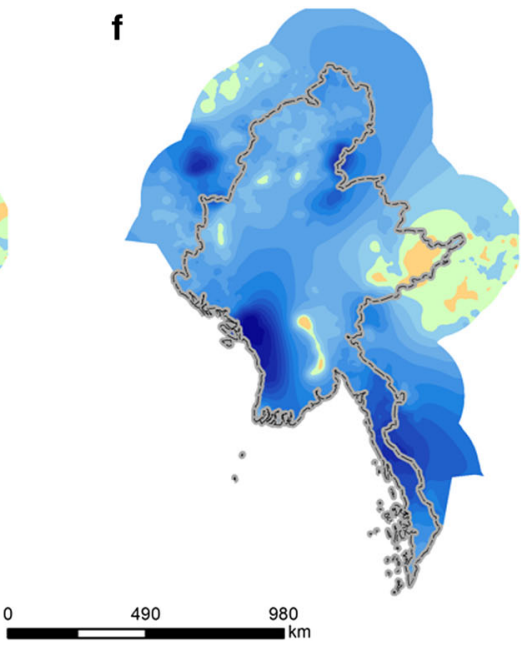

scenario. a Pipeline, b Silk Road, c Indian Highway, d Dams, e Cities, $\mathbf{d}$ Integrated

the largest clouded leopard core habitat, lies near the Indian border in Chin and Sagaing states. Development of growth and border trade centres in this area would likely substantially impact the quality and connectivity of the largest and strongest core area in all Southeast Asia (Kaszta et al. in press). Furthermore, this is also an area of relatively extensive legal and illegal coal mining and logging.

Amongst the road and railway scenarios, the Pipeline Railroad caused the highest total decrease in the strength of clouded leopard core dispersal habitats and a significant drop in population size and genetic diversity. This large impact stems from the 
fact that the railway would run through the area of the highest predicted clouded leopard density of movement, located in the centre of Rakhine state, which also happens to be an armed ethnic conflict zone. The railroad also goes through the northeast part of the country-affecting the critical corridor network linking the two largest core areas for clouded leopard across their entire range. While the Indian Highway and Silk Road had lower total impacts on the overall strength of connectivity, as measured by reduction in total summed kernel value, than the Pipeline Railroad, they had potentially large effects on population-wide connectivity by cutting major core areas into separate fragments.

Although in our analysis the development of 53 hydropower dams had the lowest impact amongst the scenarios we investigated, it is important to stress that we only modelled the nominal effect of the dams' reservoirs on habitat extent and connectivity. Development of hydropower dams is accompanied by extensive additional changes in the landscape such as new infrastructure (e.g., roads, pylons and power lines), deforestation around the reservoir and access roads, and new settlements. Therefore, the true effect of the simulated hydropower dams on clouded leopard habitat and populations over the long term is likely much greater than predicted by our model.

One of the main assumptions of this work was that a habitat suitability layer derived from presence/absence data can serve as a relatively good proxy for estimating resistance to movement. It has been showed that habitat suitability, especially when linearly transformed into resistance, performs worse in comparison with resistance developed based on movement or genetic data (e.g., Wasserman et al. 2010; MateoSanchez et al. 2015a, b). However, Zeller et al. (2018) concluded that in cases where high frequency GPS collar or genetic data are not available, habitat suitability, although weaker, may be sufficient for estimating resistance to movement. Furthermore, due to lack of empirical data or models, we used expert opinion to assess possible impacts of developments like major roads and growth/transport centres. We, however, acknowledge that resistance parametrized based on expert opinion might sometimes perform poorly (Charney 2012; Shirk et al. 2010, 2015). Therefore, future efforts should focus on acquiring clouded leopard movement or genetic data, particularly focusing on habitats strongly affected by human activities, including the regions of the development scenarios evaluated here.

The simulated 14\% reduction in clouded leopard population in the base scenario from that estimated based on habitat suitability (Macdonald et al. 2019) and the total estimated clouded leopard population (IUCN) is plausible given the rapid and recent loss of habitat in the region. However, we want to recognize that the CDPOP results are most robust for comparative purposes of differences between scenarios run with the same parameterization, and is not intended to predict with great accuracy the density, distribution or genetic diversity in 200 generations, given limited knowledge of the actual density and distribution of the current population, and estimates and assumptions in the model parameterization, which, while made based on the best current knowledge and consistent with previously published studies, are not known with high certainty.

This work presents an assessment of development impacts on forest ecosystems in Myanmar, using clouded leopard as a forest indicator and ambassador species (both an umbrella and a champion) for wider biodiversity (Macdonald et al. 2017). However, the major developments ongoing and forthcoming in Myanmar can also impact other ecosystems. Therefore, for a comprehensive assessment of developments impact on natural habitats and biodiversity in Myanmar, we advocate a broader assessment, using methodological frameworks such as those presented in this study, together with empirical data of other species representing a range of vulnerable ecosystems.

We believe that this study and the approach presented here constitutes a substantial and informative evaluation of the potential effects of several, realistic, ongoing development scenarios in Myanmar on clouded leopard populations and forest ecosystems in general and can be also applied to evaluate other development plans and species. However, this study will only be relevant to the conservation of natural resources in Myanmar if this kind of analysis is integrated into the official planning and permitting process. We hope that our approach can provide officials with a conceptual tool kit, readily adaptable to different regions, development scenarios and species. We feel that integrating realistic development scenarios at national and international scales with biologically informative analytical and modelling efforts is a critical step towards the better integration of 
development planning and biodiversity conservation, and we hope this paper is a small step toward that goal.

Acknowledgements This study was founded by grants to DWM from the Robertson Foundation and by the Rivington Winnant Memorial Fellowship awarded to ZK by the Eppley Foundation. We wish to thank International Centre for Environmental Management (ICEM) for providing data and Wildlife Conservation Society (WCS) for all their support. We thank also the government officials and NGO representatives that attended the WildCRU's informal discussions of this project in Yangon and Nay Pyi Taw, and most especially our generous hosts at the Wildlife Conservation Society, the Nature and Wildlife Conservation Division, Forest Department, Ministry of Natural Resources and Environmental Conservation (MONREC), to whose important work we deeply hope our research will contribute.

Open Access This article is licensed under a Creative Commons Attribution 4.0 International License, which permits use, sharing, adaptation, distribution and reproduction in any medium or format, as long as you give appropriate credit to the original author(s) and the source, provide a link to the Creative Commons licence, and indicate if changes were made. The images or other third party material in this article are included in the article's Creative Commons licence, unless indicated otherwise in a credit line to the material. If material is not included in the article's Creative Commons licence and your intended use is not permitted by statutory regulation or exceeds the permitted use, you will need to obtain permission directly from the copyright holder. To view a copy of this licence, visit http://creativecommons.org/licenses/by/4.0/.

\section{References}

Bowman J, Jochen A, Fahrig L (2002) Dispersal distance of mammals is proportional to home range size. Ecology 83:2049-2055

Charney ND (2012) Evaluating expert opinion and spatial scale in an amphibian model. Ecol Model 242:37-45

Compton BW, McGarigal K, Cushman SA, Gamble LR (2007) A resistant-kernel model of connectivity for amphibians that breed in vernal pools. Conserv Biol 21:788-799

Cushman SA, Elliot NB, Bauer D, Kesch K, Bahaa-el-din L, Bothwell H, Flyman M, Mtare G, Macdonald DW, Loveridge AJ (2018) Prioritizing core areas, corridors and conflict hotspots for lion conservation in southern Africa. PLoS ONE 13:e0196213

Cushman SA, Elliot NB, Macdonald DW, Loveridge AJ (2016) A multi-scale assessment of population connectivity in African lions (Panthera leo) in response to landscape change. Landsc Ecol 31:1337-1353

Cushman SA, Landguth EL (2010) Spurious correlations and inference in landscape genetics. Mol Ecol 19:3592-3602

Cushman SA, Landguth EL, Flather CH (2013a) Evaluating population connectivity for species of conservation concern in the American Great Plains. Biodivers Conserv 22:2583-2605

Cushman SA, Lewis JS, Landguth EL (2014) Why did the bear cross the road? Comparing the performance of multiple resistance surfaces and connectivity modeling methods. Diversity 6:844-854

Cushman SA, Mcrae B, Adriaensen F, Beier P, Shirley M, Zeller K (2013b) Biological corridors and connectivity. Key Topics Conserv Biol 2:384-404

Cushman SA, Shirk AJ, Landguth EL (2013c) Landscape genetics and limiting factors. Conserv Genet 14:263-274

De P, Ray J (2013) India-Myanmar connectivity: current status and future prospects. Page SSRN. https://doi.org/10.2139/ ssrn. 2260693

Dickman AJ, Hinks AE, Macdonald EA, Burnham D, Macdonald DW (2015) Priorities for global felid conservation. Conserv Biol 29:854-864

Elliot NB, Cushman SA, Loveridge AJ, Mtare G, Macdonald DW (2014a) Movements vary according to dispersal stage, group size, and rainfall: the case of the African lion. Ecology 95:2860-2869

Elliot NB, Cushman SA, Macdonald DW, Loveridge AJ (2014b) The devil is in the dispersers: predictions of landscape connectivity change with demography. J Appl Ecol 51:1169-1178

Food and Agriculture Organization of the United Nations (2015) Global Forest Resources Assessment 2015. Iatly, Rome

Frankham R (2005) Genetics and extinction. Biol Conserv 126:131-140

Gong X (2018) China Power investment corporation in Myanmar. Securing the Belt and Road Initiative. Springer, Singapore, pp 121-146

Hearn AJ, Cushman SA, Goossens B, Macdonald E, Ross J, Hunter LTB, Abram NK, Macdonald DW (2018) Evaluating scenarios of landscape change for Sunda clouded leopard connectivity in a human dominated landscape. Biol Conserv 222:232-240

Hearn AJ, Cushman SA, Goossens B, Ross J, Macdonald EA, Hunter LTB, Macdonald DW (2019) Predicting connectivity, population size and genetic diversity of Sunda clouded leopards across Sabah, Borneo. Landsc Ecol 34:275-290

Hillman J (2018) China's belt and road is full of holes. CSIS Briefs. https://www.csis.org/analysis/chinas-belt-androad-full-holes

Hughes AC (2017) Understanding the drivers of Southeast Asian biodiversity loss. Ecosphere 8:e01624

Hughes AC (2019) Understanding and minimizing environmental impacts of the Belt and Road Initiative. Conserv Biol 0:1-12

Kaszta Ż, Cushman SA, Sillero-Zubiri C, Wolff E, Marino J (2018) Where buffalo and cattle meet: modelling interspecific contact risk using cumulative resistant kernels. Ecography 41:1-11

Kaszta Ż, Cushman SA, Hearn AJ, Burnham D, Macdonald EA, Goossens B, Nathan SKSS, Macdonald DW (2019) Integrating Sunda clouded leopard (Neofelis diardi) conservation into development and restoration planning in Sabah (Borneo). Biol Conserv 235:63-76 
Kaszta Ż, Cushman SA, Macdonald DW Prioritizing habitat core areas and corridors for a large carnivore across its range. Anim Conserv (in press)

Kattelus M, Rahaman MM, Varis O (2015) Hydropower development in Myanmar and its implications on regional energy cooperation. Int J Sustain Soc 7:42

Keeley ATH, Beier P, Gagnon JW (2016) Estimating landscape resistance from habitat suitability: effects of data source and nonlinearities. Landsc Ecol 31:2151-2162

Keeley ATH, Beier P, Keeley BW, Fagan ME (2017) Habitat suitability is a poor proxy for landscape connectivity during dispersal and mating movements. Landsc Urban Plann 161:90-102

Kimura F, Umezaki S (eds) (2011) ASEAN-India connectivity: the comprehensive Asia Development Plan, Phase II. Economic Research Institute for ASEAN and East Asia

Lamb V, Dao N (2017) Perceptions and practices of investment: China's hydropower investments in Vietnam and Myanmar. Can J Dev Stud 38:395-413

Landguth EL, Cushman SA (2010) Cdpop: a spatially explicit cost distance population genetics program. Mol Ecol Resour 10:156-161

Landguth EL, Cushman SA, Murphy MA, Luikart G (2010a) Relationships between migration rates and landscape resistance assessed using individual-based simulations. Mol Ecol Resour 10:854-862

Landguth EL, Cushman SA, Schwartz MK, McKelvey KS, Murphy M, Luikart G (2010b) Quantifying the lag time to detect barriers in landscape genetics. Mol Ecol 19:4179-4191

Landguth EL, Hand BK, Glassy J, Cushman SA, Sawaya MA (2012) UNICOR: a species connectivity and corridor network simulator. Ecography 35:9-14

Macdonald EA, Cushman SA, Landguth EL, Hearn AJ, Malhi Y, Macdonald DW (2018) Simulating impacts of rapid forest loss on population size, connectivity and genetic diversity of Sunda clouded leopards (Neofelis diardi) in Borneo. PLoS ONE 13:1-22

Macdonald DW, Bothwell HM, Kaszta Ż, Ash E, Bolongon G, Burnham D, Can ÖE, Campos-Arceiz A, Channa P, Clements GR, Hearn AJ, Hedges L, Htun S, Kamler JF, Kawanishi K, Macdonald EA, Mohamad SW, Moore J, Naing H, Onuma M, Penjor U, Rasphone A, Mark RD, Ross J, Singh P, Tan CKW, Wadey J, Yadav BP, Cushman SA (2019) Multi-scale habitat modelling identifies spatial conservation priorities for mainland clouded leopards (Neofelis nebulosa). Diversity and Distributions: ddi.12967. https://onlinelibrary.wiley.com/doi/abs/10. 1111/ddi. 12967

Macdonald EA, Hinks A, Weiss DJ, Dickman A, Burnham D, Sandom CJ, Malhi Y, Macdonald DW (2017) Identifying ambassador species for conservation marketing. Glob Ecol Conserv 12:204-214

Mateo-Sánchez MC, Cushman SA, Saura S (2014) Connecting endangered brown bear subpopulations in the Cantabrian Range (north-western Spain). Anim Conserv 17:430-440

Mateo-Sánchez MC, Balkenhol N, Cushman SA, Perez T, Domínguez A, Saura S (2015a) Estimating effective landscape distances and movement corridors: comparison of habitat and genetic data. Ecosphere 6:1-16
Mateo-Sánchez MC, Balkenhol N, Cushman S, Pérez T, Domínguez A, Saura S (2015b) A comparative framework to infer landscape effects on population genetic structure: are habitat suitability models effective in explaining gene flow? Landsc Ecol 30:1405-1420

McGarigal K, Cushman SA, Ene E. (2012) FRAGSTATS v4: spatial pattern analysis program for categorical and continuous maps. University of Massachusetts, Amherst, Massachusetts, USA. goo. gl/aAEbMk

McGarigal K, Wan HY, Zeller KA, Timm BC, Cushman SA (2016) Multi-scale habitat selection modeling: a review and outlook. Landsc Ecol 31:1161-1175

Naing H, Ross J, Burnham D, Htun S, Macdonald DW. (2017) Population density estimates and conservation concern for clouded leopards Neofelis nebulosa, marbled cats Pardofelis marmorata and tigers Panthera tigris in Htamanthi Wildlife Sanctuary, Sagaing, Myanmar. Oryx 1-9

Noël S, Ouellet M, Galois P, Lapointe FJ (2007) Impact of urban fragmentation on the genetic structure of the eastern redbacked salamander. Conserv Genet 8:599-606

R Development Core Team (2013) R: a language and environment for statistical computing. R Foundation for Statistical Computing, R Development Core Team, Vienna

Rao M, Htun S, Platt SG, Tizard R, Poole C, Myint T, Watson JEM (2013) Biodiversity conservation in a changing climate: a review of threats and implications for conservation planning in myanmar. Ambio 42:789-804

Schmidt C (2012) As isolation ends, Myanmar faces new ecological risks. Science 337:796-797

Shirk AJ, Schroeder MA, Robb LA, Cushman SA (2015) Empirical validation of landscape resistance models: insights from the Greater Sage-Grouse (Centrocercus urophasianus). Landsc Ecol 30:1837-1850

Shirk AJ, Wallin DO, Cushman SA, Rice CG, Warheit KI (2010) Inferring landscape effects on gene flow: a new model selection framework. Mol Ecol 19:3603-3619

Sodhi NS, Koh LP, Brook BW, Ng PKL (2004) Southeast Asian biodiversity: an impending disaster. Trends Ecol Evol 19:654-660

Thatte P, Joshi A, Vaidyanathan S, Landguth E, Ramakrishnan U (2018) Maintaining tiger connectivity and minimizing extinction into the next century: insights from landscape genetics and spatially-explicit simulations. Biol Conserv 218:181-191

The World Commision of Dams (2000) Dams and development: a new framewor for decision-making. London and Sterling, VA

Tordoff AW, Baltzer MC, Fellowes JR, Pilgrim JD, Langhammer PF (2012) Key biodiversity areas in the Indo-Burma hotspot: process, progress and future directions. J Threatened Taxa 04:2779-2787

United Nations Development Programme. (2018) Human development indices and indicators. 2018 Statistical Update: New York

Van Noordwijk AJ (1994) The interaction of inbreeding depression and environmental stochasticity in the risk of extinction of small populations. Conserv Genet 68:131-146

Wasserman TN, Cushman SA, Schwartz MK, Wallin DO (2010) Spatial scaling and multi-model inference in landscape 
genetics: martes americana in northern Idaho. Landsc Ecol 25:1601-1612

Webb EL, Phelps J, Friess DA, Rao M, Ziegler AD (2012) Environment-friendly reform in Myanmar. Science 336:295-296

Whitmee S, Orme CDL (2013) Predicting dispersal distance in mammals: a trait-based approach. J Anim Ecol 82:211-221

Wildlife Conservation Society (WCS) (2012) Myanmar biodiversity conservation investment vision. Wildlife Conservation Society, Yangon
Yu H (2017) Motivation behind China's 'one belt, one road' initiatives and establishment of the Asian infrastructure investment bank. J Contemp China 26:353-368

Zeller KA, Jennings MK, Vickers TW, Ernest HB, Cushman SA, Boyce WM (2018) Are all data types and connectivity models created equal? Validating common connectivity approaches with dispersal data. Divers Distrib 24:868-879

Publisher's Note Springer Nature remains neutral with regard to jurisdictional claims in published maps and institutional affiliations. 